\title{
Oral neural tumours: A diagnostic challenge-report of two
}

\section{cases}

\author{
Andreadis Dimitrios*, Stergiadou Effimia, Anagnostou Eleftherios, and Poulopoulos Athanasios \\ Department of Oral Medicine/Pathology, School of Dentistry, Aristotle University of Thessaloniki, Greece
}

\begin{abstract}
Introduction-purpose: Neural tissue tumors are uncommon in oral cavity easily misdiagnosed as fibroma or other reactive tumorous entities. We report two cases of benign tumors (traumatic neuroma of lip and schwannoma of tongue) of neural origin with diagnostic importance.

Case presentation: A 9-year-old girl presented with painless tumorous lesion on the lower lip with 5 months duration and a 50 -year-old woman with a painful nodular lesion on the tip of tongue for more than 1 year. Both lesions were initially diagnosed as fibroma but the biopsies after total excision confirmed the diagnosis of traumatic neuroma and schwannoma, respectively.

Discussion: The increase of both lesions was slow, and the pain was an important finding in case of Schwannoma. Also, the lesions were located in areas easily traumatized and the surface of mucosa in Schwannoma was not intact. The final diagnosis of intraoral tumorous-like lesion should always include biopsy in order to reveal their exact nature avoiding recurrence.

Conclusion: Tumors of neural origin could rarely lead to diagnostic pitfalls in patients of any age. Biopsy and possibly Immunohistochemistry can confirm the nature of such a lesion with impact on therapy and prognosis. Traumatic reactive lesions (fibromas), HPV-related lesions or other benign or malignant tumors could be included in the differential diagnosis.
\end{abstract}

\section{Introduction}

Oral benign lesions of neural origin may pretend fibrous reactive lesions leading to misdiagnosis. Traumatic neuroma is a well-known entity involving peripheral nerves, which occurs following trauma or surgery [1]. They can occur at any age but are most often diagnosed in young and middle-aged adults $[2,3]$. The lesion is not a true neoplasm, but it represents a frustrated attempt at nerve reparation and an exaggerated response to injury, consisting of reactive hyperplasia of the nerve tissue [4]. Neuromas can arise from different types of nervous tissue, including the nerve fibers and their myelin sheath. The lesion develops most commonly in the mental foramen, lower lip and tongue [4].

Schwannomas (neurilemomas) on the other hand are benign neoplasms, consisting of Schwann cells. In less than 1\% malignant transformation may be observed (neurofibrosarcoma) [5]. The tumor cells always are found at the outside zone of the nerve, but the tumor itself may either push the nerve aside. Schwannomas are relatively slow-growing tumors. Being mostly asymptomatic and slowly growing, schwannomas commonly occur in the age range of 8-72 years, with an average age of about 34 years and with a definite female predilection $[6,7]$.

The aim of this paper is to present two cases of neurological benign tumors in the oral cavity and to highlight the importance of the histological examination of these tumors in order to avoid misdiagnosis.

\section{Materials and methods}

We present two clinical cases including a 9-year-old child (girl) with a small painless tumorous lesion on the lower lip for over 5 months. In the second case a 50-year-old woman was presented with a painful multi-lobulated lesion for over a year at the top of the tongue.

\section{Results}

The first case was a 9-year-old child (girl) presented with small, painless, tumorous lesion of the lower lip 5 months ago. Clinically the tumor was lobulated, $0,7 \times 0,6 \times 0,3 \mathrm{~cm}$ in dimension, solid elastic in palpation, with whitish surface due to hyperkeratosis, initially considered as fibroma (Figure 1). The lesion was completely excised after local anesthesia. Microscopically, the covering squamous epithelium was keratinized without atypia. Several, diffuse enriched bundles, which fibrous tissue with sparse lymphocytic proliferation was observed beneath epithelium (Figure 2, X100, magnification). At the site of superficial stroma mild infiltration of neutrophils were seen. In the fibrous tissue, scratchy, small groups of entrapped, filamentary fibers and elongated cells are observed (Figure 3, x200 magnification). Based on the histologic findings the diagnosis of traumatic neuroma of the lower lip was settled. No recurrence is observed after 14 monthfollow-up.

In the second case a 50-year-old female presented with a mildly painful multi-lobulated lesion for over a year at the top of the tongue, with solid-elastic consistency that has been initially considered as traumatic fibroma (Figure 4). Clinically this tumor had also a whitish

*Correspondence to: Andreadis Dimitrios, Department of Oral Medicine/ Pathology, School of Dentistry, Aristotle University of Thessaloniki, Greece, Tel: +302310999538; E-mail: dandrea@dent.auth.gr

Key words: oral traumatic neuroma, oral schwannoma, antoni-A, antoni-B cells, verocay bodies

Received: May 03, 2019; Accepted: May 17, 2019; Published: May 20, 2019 


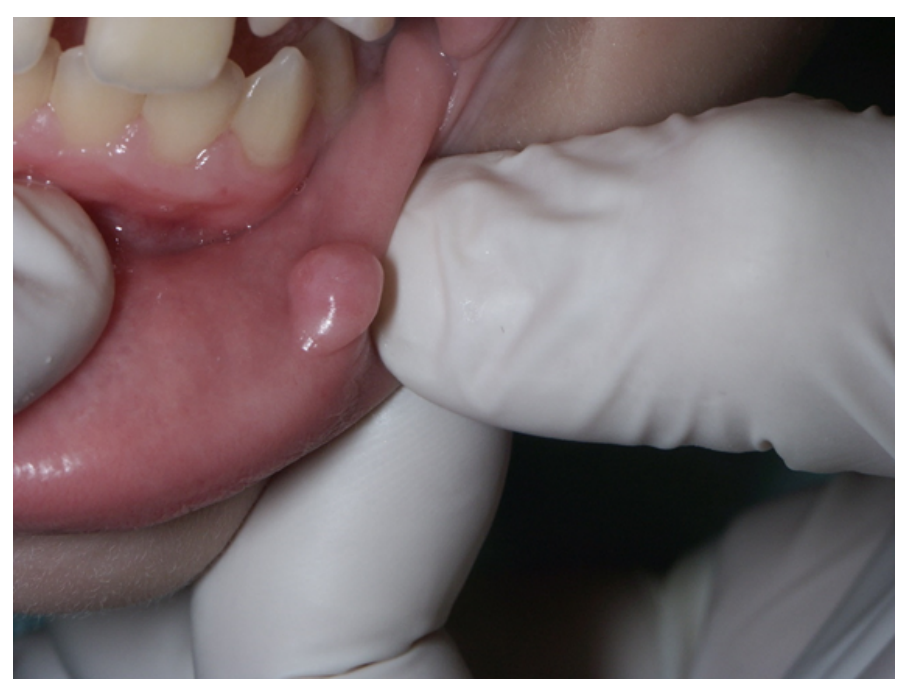

Figure 1. Tumorous lesion with solid consistency at the mucosal part of the lower lip.

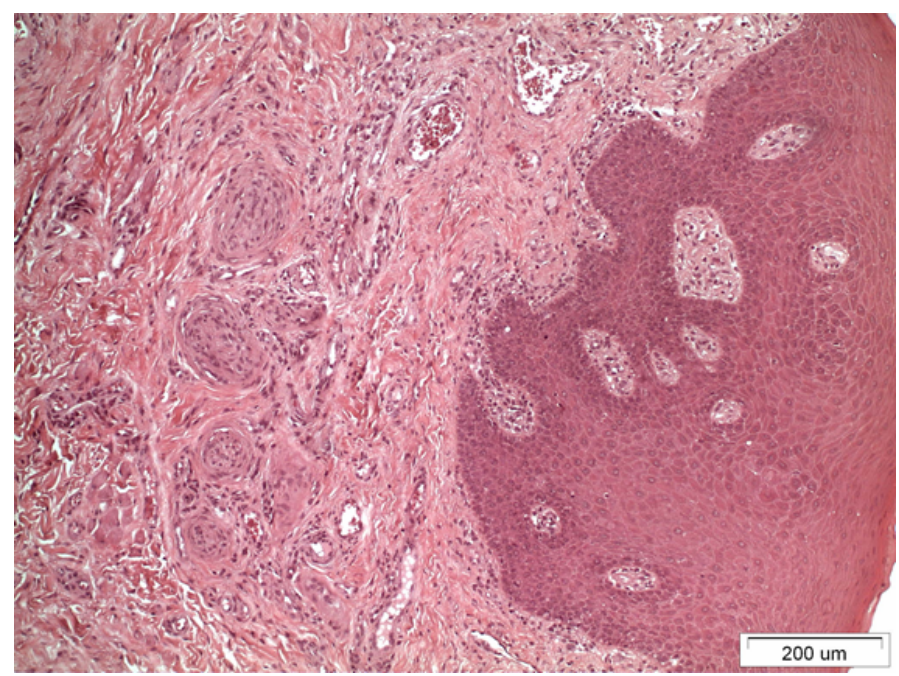

Figure 2. Diffuse enriched bundles, which fibrous tissue with sparse lymphocytic proliferation was observed beneath epithelium (x100 magnification).

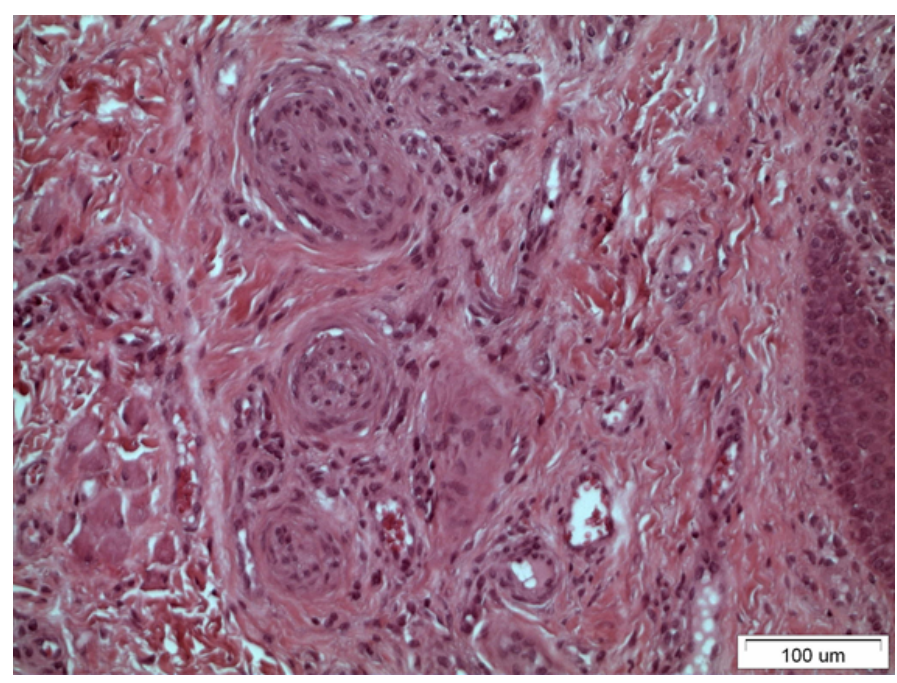

Figure 3. Fibrous tissue with scratchy, small groups of entrapped, filamentary fibers (x200 magnification).

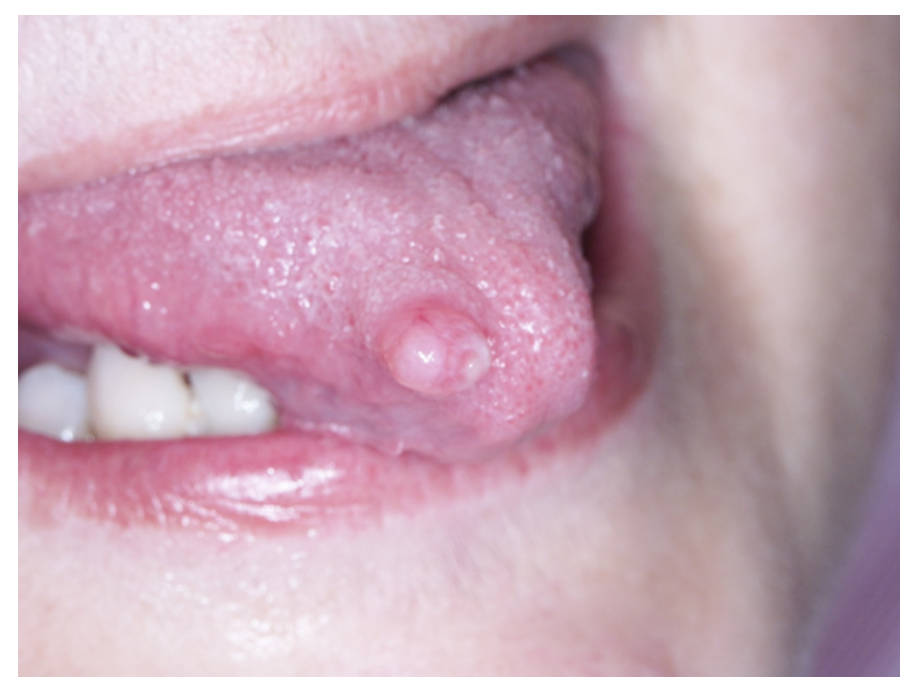

Figure 4. Tumorous multi-lobulated tumorous lesion at the top of the tongue.

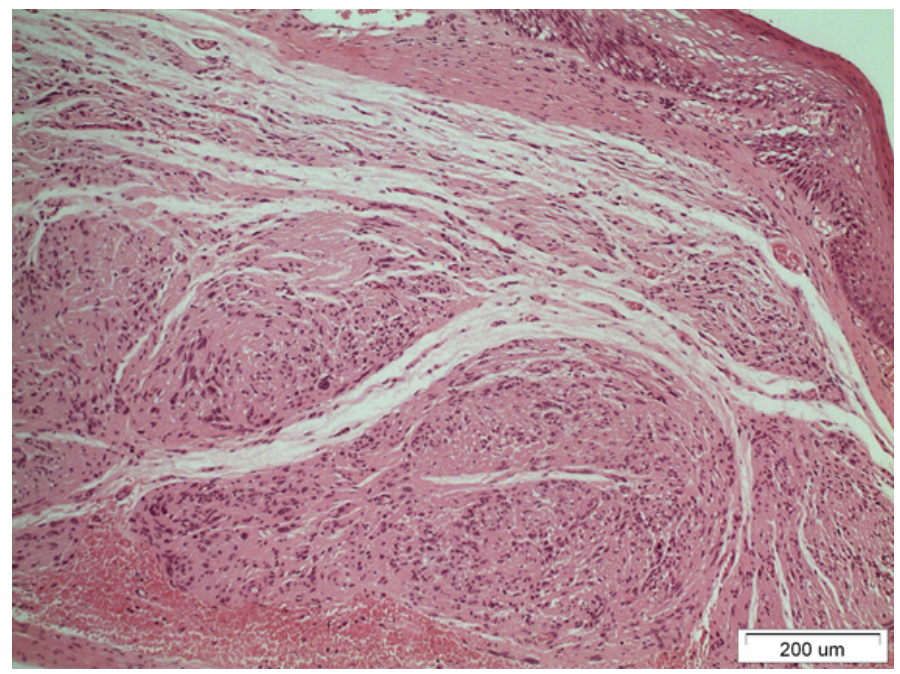

Figure 5. Regions of high cell accumulation consisted of a pattern of spindle cells arranged in intersecting bundles (x100 magnification).

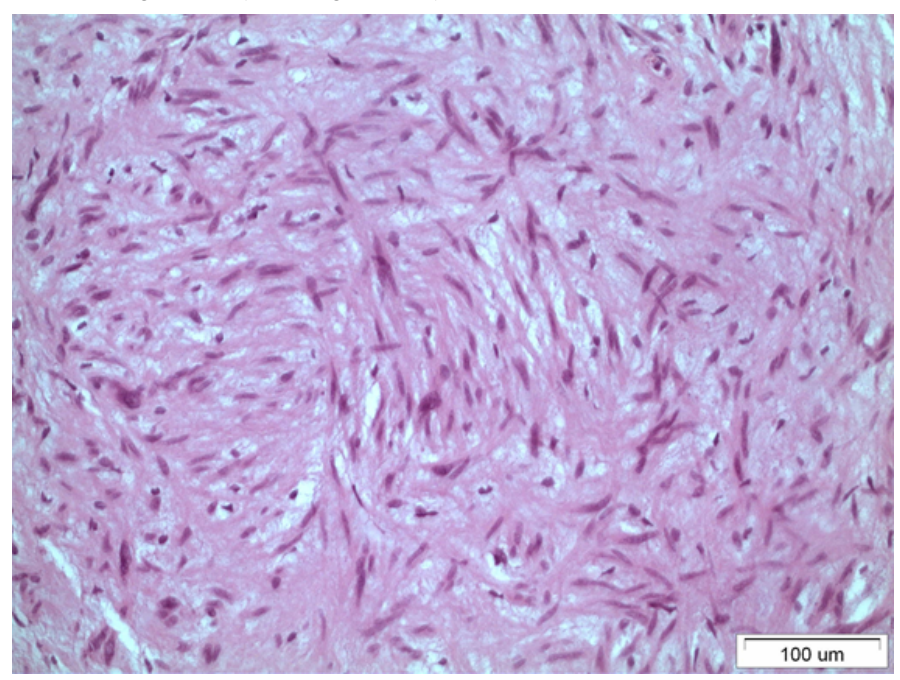

Figure 6. Two rows of aligned nuclei in a palisading formation (Verocay bodies). Also, some areas are less oedematous with less cellularity with loosely arranged cells (Antoni-B) and spindle cells arranged, with focal pleomorphy (Antoni-A structure) without mitotic activity (x200 magnification). 
surface, was multi-lobulated and its major diameter was approximately $1 \mathrm{~cm}$. The lesion was totally excised under local anesthesia. Microscopically, a tumor with mesenchymal neoplastic cells was seen, characterized by regions with dense cellular accumulation consisted of a pattern of spindle cells arranged in intersecting bundles (spindle cell battle formation), with focal pleomorphy (Antoni A structure), but free of mitotic atypia (Figure 5). These cells they present focally, two rows of aligned nuclei in a palisading formation (Verocay bodies). Also, some areas were less oedematous with less cellularity consist of loosely arranged cells (Antoni B) (Figure 6). The covering oral mucosa showed ulceration. The neoplastic cells were stained for S-100 marker, moderately. Based on the histologic findings the diagnosis of Schwannoma of the tongue was settled. No recurrence is observed after 8 month-follow-up.

\section{Discussion}

The neuromas and schwannomas are relatively uncommon lesions in oral mucosa $[8,9]$. The most common symptom of traumatic neuromas is pain, due to compression of nerves by the tumor, although studies indicate it is present in only $25-30 \%$ of the cases [10,11]. Jones and Franklin in 2005 reviewed 44,007 oral and maxillofacial tumors and found only 149 cases (0.34\%) [2]. Traumatic neuromas can occur at any age but are most often diagnosed in young and middle-aged adults $[2,11]$. Histopathologically, traumatic neuromas typically pre-sent as non-encapsulated lesions, containing a large amount of haphazardly arranged nerve fascicles, within a densely collagenous and fibroblastic stroma. Occasionally, scar tissue may also be seen [3]. The treatment of choice is nerve sparing surgical excision. An optimal technique, with minimal manipulation and severance of nerve fiber, is essential for adequate outcome [4].

Neurilemmoma (Schwannoma) is a rare, benign, encapsulated perineural tumor of neuroectodermal origin that is derived from the Schwann cells of the neural sheath [5]. It has been considered that they arise directly from the neural tube or from the neural crest [8]. Being asymptomatic and slowly growing, Schwannomas most commonly occur in the age range of 8-72 years, with a female predilection [12]. Histologic examination shows cellular Antoni-A zones, which contain foci of nuclear palisading around cell processes (Verocay bodies), which were admixed with less cellular, partially myxoid Antoni-B cell zones, which closely resembled Neurofibromas. This was characteristic and suggestive of Schwannomas. The constituent Schwann cells have eosinophilic, fibrillar-appearing cytoplasm and elongated, wavy nuclei. The relative percentages of Antoni-A and B cell zones vary from case to case. These could be thick walled, hyalinized blood vessels and extensive cystic changes, which resembled thrombosed blood vessels, with only a thin peripheral rim of neoplastic cells [7]. Immunohistochemistry acts as an adjunct in giving a definitive diagnosis. Schwannomas of all types are uniformly and intensely S-100 protein positive and they express glial fibrillary acidic protein (GFAP) in most cases $[13,14]$. The pericapsular region of a Schwannoma may contain EMA- and CD34- positive cells
[14]. The recurrence and malignant transformation of Neurilemmoma is exceedingly rare and the prognosis is usually excellent after proper total excision [5].

\section{Conclusion}

It is of high importance to mention about the differential diagnosis of the traumatic neuroma and schwannoma from fibroma in oral mucosa. In the first case the final diagnosis was settled by the histological examination. The clinical characteristics and histological examination are also important for the differential diagnosis of schwannoma and fibroma, because there is no pain present in some cases of schwannomas. Noteworthy, recurrence and malignant transformation may happen in $1 \%$ of Schwannoma cases. In both cases the treatment option is the surgical complete excision.

\section{References}

1. Lee EJ, Calcaterra TC, Zuckerbraun L (1998) Traumatic neuromas of the head and neck. Ear Nose Throat J 77: 670-674. [Crossref]

2. Jones AV, Franklin CD (2006) An analysis of oral and maxillofacial pathology found in adults over a 30-year period. J Oral Pathol Med 35: 392-401. [Crossref]

3. Vora AR, Loescher AR, Craig GT, Boissonade FM, Robinson PP (2005) A ligh microscopical study on the structure of traumatic neuromas of the human lingual nerve. Oral Surg Oral Med Oral Pathol Oral Radiol Endod 99: 395-403. [Crossref]

4. Jham BC, Costa NL, Batista AC, Mendonça EF (2014) Traumatic neuroma of the mandible: A case report with spontaneous remission. J Clin Exp Dent 6: e317-e320. [Crossref]

5. Parhar S, Singh HP, Nayyar A, Manchanda AS (2014) Intra - Oral Schwannoma - A Case Report. J Clin Diagn Res 8: 264-265. [Crossref]

6. Chi CA, Carey J, Muller S (2003) Intraosseous schwannoma of the mandible: A case report and review of literature. Oral Surg Oral Med Oral Path Oral Radiol Endod 96: 54-65. [Crossref]

7. Aswath N, Manigandan T, Sankari SL, Yogesh L (2019) A rare case of palatal schwannoma with literature review. J Oral Maxillofac Pathol 23: S36-S39. [Crossref]

8. Weirs S, JR Goldblum (2001) Saint Louis Missoury: Enzinger and Weiss's Soft Tissue Tumors. (4 $4^{\text {th }}$ Edn), Mosby 725: 1146-1167.

9. Hatziotia JC, Asprides H (1967) Neurilemoma (schwannoma) or the oral cavity. Oral Surg Oral Med Oral Pathol 24: 510-526. [Crossref]

10. Sist TC Jr, Greene GW (1981) Traumatic neuroma of the oral cavity. Re- port of thirtyone new cases and review of the literature. Oral Surg Oral Med Oral Pathol 51: 394402. [Crossref]

11. Alotaibi O, Al Sheddi M (2016) Neurogenic tumors and tumor-like lesions of the oral and maxillofacial region: A clinicopathological study. Saudi Dent $J$ 28: 76-79. [Crossref]

12. Peszkowski MJ, Larsson A (1990) Extraosseous and intraosseous oral traumatic neuromas and their association with tooth extraction. J Oral Maxillofac Surg 48: 963967. [Crossref]

13. Scheithauer BW, Woodruff JM, Erlandson RA (1999) Armed Forces Institute of Pathology. ( $3^{\text {rd }}$ Edn), Tumors of the peripheral Nervous system. In Atlas of Tumor Pathology. pp: 303-369.

14. Folpe AL, Billings SD, McKenney JK (2002) Expression of claudin a recently described tight junction-associated protein, distinguishes soft tissue perineurioma from potential mimics. Am J Surg Pathol 26: 1620-1626. [Crossref]

Copyright: (C2019 Dimitrios A. This is an open-access article distributed under the terms of the Creative Commons Attribution License, which permits unrestricted use, distribution, and reproduction in any medium, provided the original author and source are credited. 